\title{
Altered CSNK1E, FABP4 and NEFH protein levels in the dorsolateral prefrontal cortex in schizophrenia
}

\author{
Raquel Pinacho ${ }^{\mathrm{a}}$, Núria Villalmanzo ${ }^{\mathrm{a}}$, J. Javier Meana ${ }^{\mathrm{b}}$, Isidre Ferrer ${ }^{\mathrm{c}}$, Adriana Berengueras ${ }^{\mathrm{d}}$, Josep M. Haro ${ }^{\mathrm{a}}$, \\ Judit Villén ${ }^{\mathrm{e}}$, Belén Ramos ${ }^{\mathrm{a}, *}$

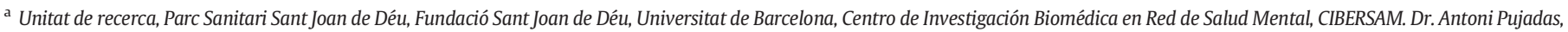 \\ 42, Sant Boi de Llobregat, 08830 Barcelona, Spain

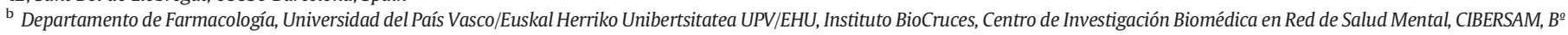 \\ Sarriena s/n, 48940 Leioa, Bizkaia, Spain

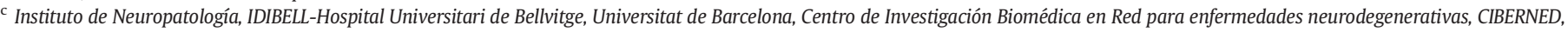 \\ Feixa Llarga s/n, Hospitalet de LLobregat, 08907 Barcelona, Spain

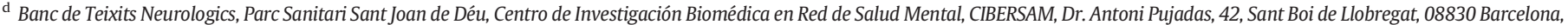 \\ Spain \\ e Genome Sciences Department, School of Medicine, University of Washington, 3720 15th Ave NE, Seattle 98195, WA, USA
}

\section{A R T I C L E I N F O}

\section{Article history:}

Received 24 October 2015

Received in revised form 15 March 2016

Accepted 27 April 2016

Available online $\mathrm{xxxx}$

\section{Keywords:}

Schizophrenia

Postmortem dorsolateral prefrontal cortex

Proteomics

CSNK1E

FABP4

$\mathrm{NEFH}$

\begin{abstract}
A B S T R A C T
Schizophrenia constitutes a complex disease. Negative and cognitive symptoms are enduring and debilitating components of the disorder, highly associated to disability and burden. Disrupted neurotransmission circuits in dorsolateral prefrontal cortex (DLPFC) have been related to these symptoms. To identify candidates altered in schizophrenia, we performed a pilot proteomic analysis on postmortem human DLPFC tissue from patients with schizophrenia $(n=4)$ and control $(n=4)$ subjects in a pool design using differential isotope peptide labelling followed by liquid chromatography tandem mass spectrometry (LC-MS/MS). We quantified 1315 proteins with two or more unique peptides, 116 of which showed altered changes. Of these altered proteins, we selected four with potential roles on cell signaling, neuronal development and synapse functioning for further validation: casein kinase I isoform epsilon (CSNK1E), fatty acid-binding protein 4 (FABP4), neurofilament triplet H protein (NEFH), and retinal dehydrogenase 1 (ALDH1A1). Immunoblot validation confirmed our proteomic findings of these proteins being decreased in abundance in the schizophrenia samples. Additionally, we conducted immunoblot validation of these candidates on an independent sample cohort comprising 23 patients with chronic schizophrenia and 23 matched controls. In this second cohort, CSNK1E, FABP4 and NEFH were reduced in the schizophrenia group while ALDH1A1 did not significantly change. This study provides evidence indicating these proteins are decreased in schizophrenia: CSNK1E, involved in circadian molecular clock signaling, FABP4 with possible implication in synapse functioning, and NEFH, important for cytoarchitecture organization. Hence, these findings suggest the possible implication of these proteins in the cognitive and/or negative symptoms in schizophrenia.
\end{abstract}

(c) 2016 Elsevier B.V. All rights reserved.

\section{Introduction}

Schizophrenia is a complex disorder in which genetic and environmental factors are proposed to interact and contribute to the emergence of the disease. These factors may converge and impact upon the same physiopathological pathways in the brain, affecting neural microcircuitry (Harrison and Weinberger, 2005; Sullivan, 2012).

Negative symptoms (e.g. lack of volition, poor social functioning, and blunted affect) and cognitive impairments (e.g. deficits in executive functions and working memory) are core symptoms of schizophrenia, and are the most resilient to currently available treatments (Gold,

\footnotetext{
* Corresponding author.

E-mail address: bramos@fsjd.org (B. Ramos).
}

2004; Millan et al., 2014; Stahl and Buckley, 2007). The dorsolateral prefrontal cortex (DLPFC) is involved in both cognitive deficits (Frith and Dolan, 1996; Lewis and Moghaddam, 2006; Teffer and Semendeferi, 2012) and negative symptoms (Semkovska et al., 2001; Toda and Abi-Dargham, 2007). A dysfunction in this region has been widely described in functional and structural imaging studies and in many molecular reports (English et al., 2011; Goldstein et al., 1999; Konradi, 2005; Wong and Van Tol, 2003). Several neurotransmitter systems have been implicated in this dysfunction. Hypodopaminergic activity has been associated with cognitive impairments and negative symptoms (Kienast and Heinz, 2006; Toda and Abi-Dargham, 2007). Excitatory glutamatergic and inhibitory GABAergic neurotransmission systems have also been implicated in these symptoms in schizophrenia (Krystal et al., 1994; Lewis and Moghaddam, 2006; Moghaddam and 
Javitt, 2012). However, an integrative understanding of common molecular pathways affected by these systems is just starting to be unveiled.

Previous proteomic and transcriptomic screenings have reported mitochondrial function, cytoskeleton formation, and oligodendrocytes to be consistently altered in the DLPFC in schizophrenia (English et al., 2011; Konradi, 2005; Martins-de-Souza et al., 2010a; Martins-de-Souza et al., 2009a). These approaches are useful tools that help to provide an overall picture of altered common functions and pathways in human tissues. However, there is still missing information of altered proteins in schizophrenia, which could potentially be obtained using alternative proteomic approaches.

Here, we designed a pilot quantitative proteomic analysis using differential isotope peptide labelling followed by liquid chromatography fractionation and tandem mass spectrometry (LC-MS/MS) in grey

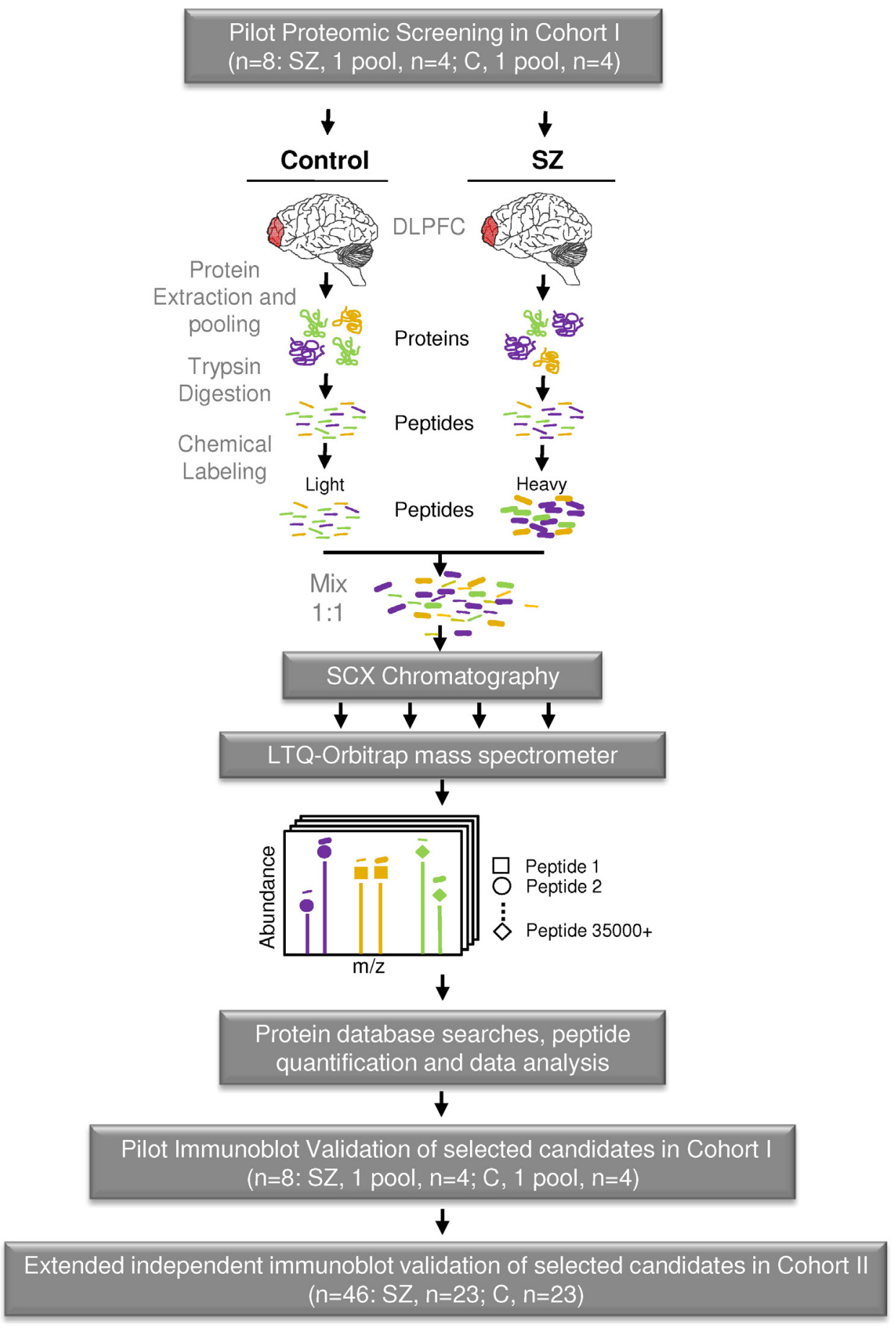

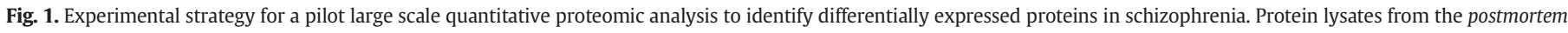

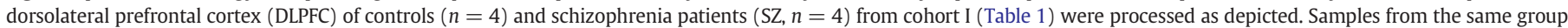

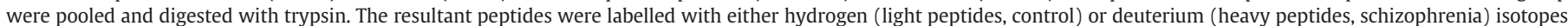

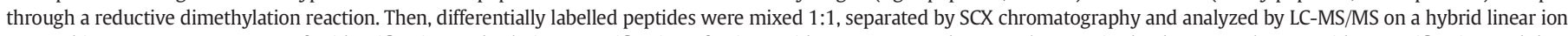

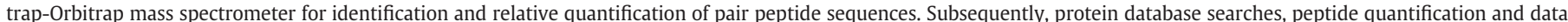

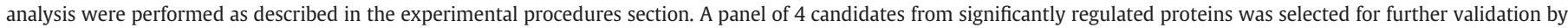

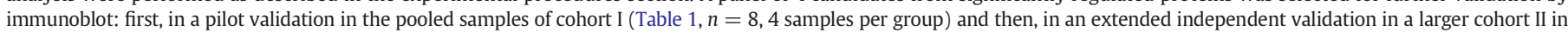
individual samples (Table $1 ; n=46 ; 23$ samples per group). 
matter DLPFC samples from four pooled schizophrenia and four pooled control individuals with the end goal to discover possible common altered proteins across patients with schizophrenia for further validation of selected candidates in a larger cohort of individual samples (Fig. 1). Thus, after the initial proteomic screen, 23 samples per group (control and SZ groups) were used in this study for independent validation of three candidate proteins by immunoblot in individual patients. Our validation was focused on novel altered protein isoforms in schizophrenia with a plausible role on cell signaling, neuronal development and synapse functioning.

\section{Materials and methods}

\subsection{Brain tissue samples}

For the pilot proteomic analysis, we used postmortem human brain tissue from the DLPFC of patients with schizophrenia (1 pool composed of $4 \mathrm{SZ}$ patients) and control subjects with no history of psychiatric episodes ( 1 pool composed of 4 control individuals) from the UPV/EHU brain collection (see more details in Supplementary material and Table 1). Samples were obtained at autopsy by forensic pathologists under research policies with postmortem samples. All deaths were subjected to retrospective analysis for previous medical diagnosis. Subjects with antemortem criteria for paranoid schizophrenia according to the Diagnostic and Statistical Manual of Mental Disorders (DSM-IV) that died by suicide were matched to control subjects who died by accidental causes in a paired design, based on gender, age, and postmortem delay (PMD). Toxicological screening for antipsychotics, antidepressants, and other drugs was performed at the National
Institute of Toxicology, Madrid, Spain. We further validated the candidates identified in the quantitative proteomic assay in an independent set of postmortem human DLPFC of patients with chronic schizophrenia $(n=23)$ and control individuals with no history of psychiatric episodes $(n=23)$ from the collection of neurologic tissues of Parc Sanitari Sant Joan de Déu (Roca et al., 2008) and the Institute of Neuropathology Brain Bank (HUB-ICO-IDIBELL Biobank) (Table1). All SZ patients were institutionalized donors with a long duration of the illness (Table 1) who had no history of neurological episodes. The study was approved by the Institutional Ethics Committee of Parc Sanitari Sant Joan de Déu. We matched schizophrenia and control groups by gender (only male patients were included), age, postmortem delay and $\mathrm{pH}$. Experienced clinical examiners interviewed each donor antemortem to confirm schizophrenia diagnosis according to the Diagnostic and Statistical Manual of Mental Disorders (DSM-IV) and International Classification of Diseases 10 (ICD-10) criteria. All deaths were due to natural causes. Neuropathologists from the Institute of Neuropathology Brain Bank (HUB-ICO-IDIBELL Biobank) examined the contralateral hemisphere for signs of neurodegenerative disorders in both schizophrenia patients and control. $76.1 \%$ of both schizophrenia and control groups showed low degree of Alzheimer disease-related changes (Stage $\leq$ III, Braak and Braak scale (Braak et al., 2006; Braak and Braak, 1991)). The last daily chlorpromazine equivalent dose for the antipsychotic treatment of patients was calculated based on the electronic records of last drug prescriptions administered up to death as described previously (Gardner et al., 2010) (Table 1). Patients and controls were chosen among the collected brains on the basis, whenever possible, of the following criteria: (a) negative medical information on the presence of neurological disorders or drug abuse, (b) accidental or natural cause

Table 1

Demographic, clinical and tissue related features of cases.

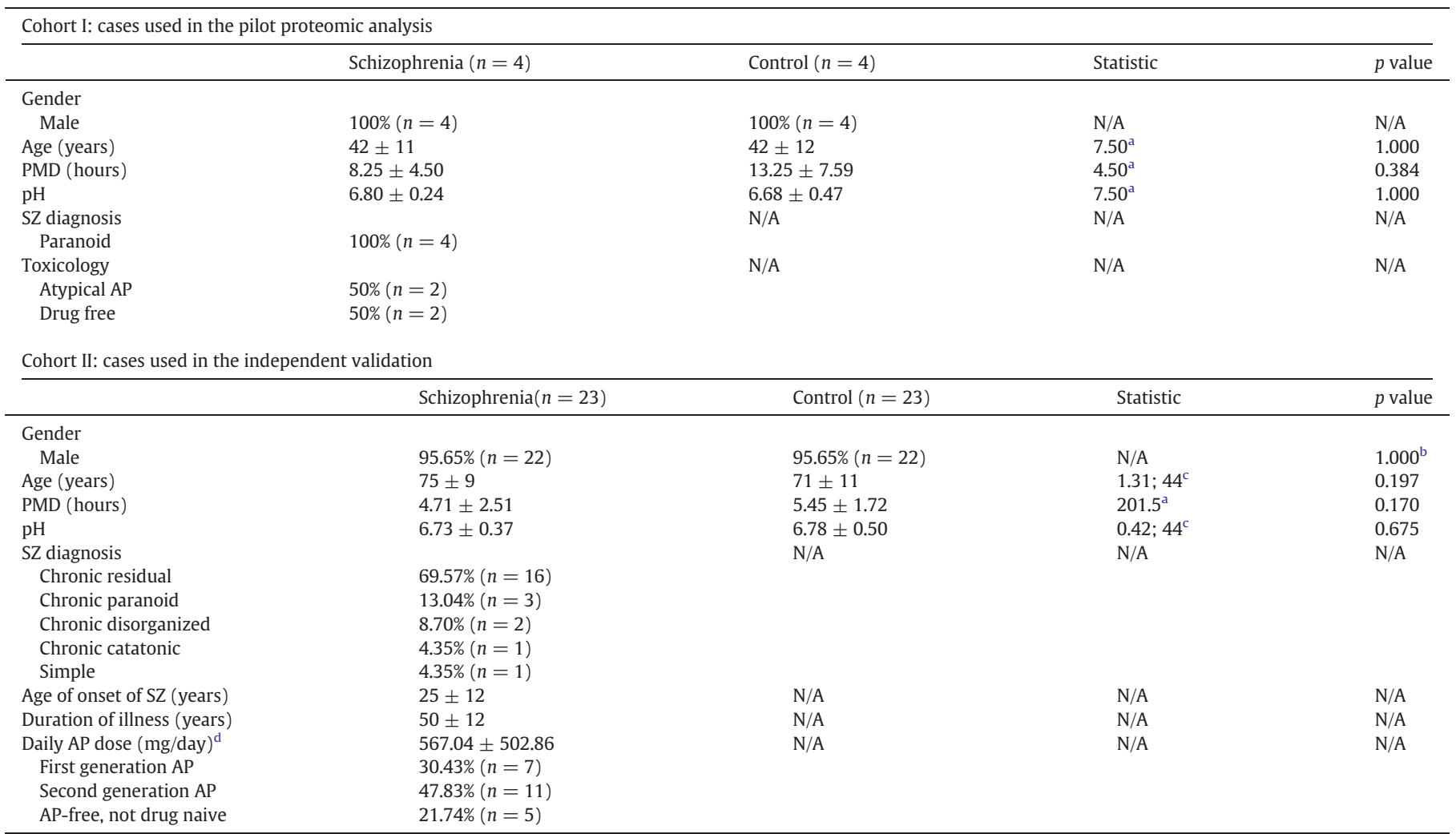

Mean \pm standard deviation or relative frequency are shown for each variable; PMD, postmortem delay; SZ, schizophrenia; AP, antipsychotics; N/A, not applicable

a Mann-Whitney U is shown for non-parametric variables.

b Frequencies were analyzed by Fisher's exact test.

c T-statistic and degrees of freedom are shown for parametric variables.

d Last chlorpromazine equivalent dose was calculated based on the electronic records of drug prescriptions of the patients as described (Gardner et al., 2010). 
of death that does not compromise the integrity of the region of interest, and (c) brain $\mathrm{pH}$ higher than 6 . Samples were codified by the brain bank staff according to data protection procedures.

\subsection{Protein extraction}

Specimens of the DLPFC (Brodmann area 9), extending from the pial surface to white matter and only including grey matter were dissected from coronal slabs stored at $-80{ }^{\circ} \mathrm{C}$ using a standard human brain atlas (Mai et al., 1997). Due to collection methods in each institution, left dorsolateral prefrontal cortex from schizophrenia patients was paired with the contralateral hemisphere from controls. Protein extracts were prepared from tissue samples using NP40 lysis buffer as described previously (Pinacho et al., 2011). Protein concentration was determined by Bradford assay (Biorad, Hercules, CA, USA).

\subsection{Mass spectrometry analysis}

$500 \mu \mathrm{g}$ of total protein extracts from control and schizophrenia lysates (one pool per group composed of four samples, $125 \mu \mathrm{g}$ of protein per sample) were each reduced with $5 \mathrm{mM}$ dithiothreitol at $56{ }^{\circ} \mathrm{C}$ for $30 \mathrm{~min}$ in $50 \mathrm{mM}$ Tris $\mathrm{pH} 8$, alkylated with $15 \mathrm{mM}$ iodoacetamide in the dark at room temperature for $30 \mathrm{~min}$ and quenched with additional $5 \mathrm{mM}$ dithiothreitol for $15 \mathrm{~min}$. Each extract was digested with $5 \mathrm{ng} / \mu \mathrm{L}$ trypsin in $50 \mathrm{mM}$ Tris, $1 \mathrm{mM} \mathrm{CaCl}_{2} \mathrm{pH} 8$ at $37^{\circ} \mathrm{C}$ for $16 \mathrm{~h}$. Peptides were desalted by reversed-phase in a Sep-Pak $\mathrm{tC}_{18}$ cartridge ( $100 \mathrm{mg}$, Waters Associates, Milford, MA, USA). Peptide mixtures were resuspended in $500 \mu \mathrm{L}$ of $1 \mathrm{M}$ HEPES $\mathrm{pH} 7.5$ and subjected to a reductive dimethylation reaction as described previously (Khidekel et al., 2007). The light and heavy dimethylated peptide solutions were mixed $1: 1$. Peptides were desalted by reversed-phase in a Sep-Pak $\mathrm{tC}_{18}$ cartridge and subjected to strong cation exchange chromatography on a polysulfoethyl A column. Twelve fractions were collected over 48-min in a gradient of $\mathrm{KCl}$ in $5 \mathrm{mM}$ potassium phosphate, $30 \% \mathrm{ACN}$, and dried by vacuum centrifugation. Peptide fractions were resuspended in $1 \mathrm{~mL} 0.1 \%$ trifluoroacetic acid, desalted by reversed-phase in a Sep-Pak $\mathrm{tC}_{18}$ cartridge and dried by vacuum centrifugation. Peptides were resuspended in $5 \% \mathrm{ACN}$ and $4 \%$ formic acid for LC-MS/MS analysis. Each peptide fraction was separated by reverse phase chromatography on a capillary $C_{18}$ column and analyzed online on a hybrid linear ion trap Orbitrap (LTQ-Orbitrap XL, Thermo Fisher Scientific, San Jose, CA, USA) mass spectrometer. For each cycle, one full MS scan acquired at high mass resolution (AGC target $=1 \times 10^{6}$, maximum ion injection time $=1000 \mathrm{~ms}$ ) in the Orbitrap analyser was followed by $10 \mathrm{MS} / \mathrm{MS}$ spectra on the linear ion trap (AGC target $=5 \times 10^{3}$, maximum ion injection time $=120 \mathrm{~ms}$ ) for the ten most abundant precursor ions. Fragmented precursor ions were dynamically excluded from further selection for $35 \mathrm{~s}$. Ions were also excluded if their charge was either $<2$ or unassigned. All spectra were acquired in centroid mode.

\subsection{Protein database searches, peptide quantification and data analysis}

Raw files were converted to mzXML format using ReadW version 4.3.1 using default parameters. MS/MS spectra were searched against a concatenated target-decoy IPI human protein database (version 3.20, $n=61.225$ target sequences) using the Sequest algorithm. Search parameters included fully tryptic enzyme specificity with up to two missed cleavages permitted, mass tolerance of $50 \mathrm{ppm}$ for the precursor and $1 \mathrm{Da}$ for fragments ions, fixed modifications of carboxamidomethylation on cysteines $(+57.02146)$ and dimethylation on lysines and peptide $N$-termini $(+28.03130)$, and as variable modifications methionine oxidation $(+15.99491)$ and the difference between heavy ( 6 deuterium) and light dimethyl on lysines and peptide $N$-termini $(+6.03766)$. Peptide matches were filtered to $<1 \%$ false-discovery rate using the target-decoy database strategy. Peptides matching to multiple proteins were arbitrarily assigned to the protein first listed in the database. Peptides were quantified using in-house software by peak-area integration, and heavy/light peptide ratios were calculated. Among the set of independent measurements retained for each protein, the median of the $\log _{2}$ heavy/light ratio of all peptides of the same protein was used to determine the protein ratio, and the standard deviation (SD) was calculated (Supplementary Data 1). Quality cutoffs were as described previously (Baek et al., 2008).

\subsection{Immunoblotting}

Validation of candidate proteins was approached in two steps. A first pilot validation was performed in the same pooled protein lysates analyzed in the proteomic analysis (a control pool and a schizophrenia pool each comprising equal amounts of protein lysates from four different samples). This was followed by an extensive validation in an independent cohort of 46 samples. Both cohorts are described in Section 2.1. In both validation steps $50 \mu \mathrm{g}$ of total protein lysates were resolved by SDS-PAGE electrophoresis and immunoblotted with polyclonal antibody against FABP4 (ab23693, Abcam, Cambridge, UK); NEFH (ab40796, Abcam); and monoclonal antibodies against CSNK1E (ab82426, Abcam); ALDH1A1 (ab52492, Abcam) $\alpha$-tubulin (T6199, Sigma-Aldrich, St Louis, MO, USA); $\beta$-actin (A5316, Sigma-Aldrich) and glyceraldehyde-3-phosphate dehydrogenase (GAPDH) (MAB374, Millipore-Chemicon). All proteins were detected by a unique band at the predicted molecular weight. Densitometric quantification of candidate proteins was performed using Quantity One software (BioRad). Values were normalized to the geometric mean of $\alpha$ tubulin, $\beta$-actin and GAPDH, and a control reference sample.

\subsection{Data and statistical analysis}

In the pilot protein analysis, a quality cutoff for protein determinations was set to $\geq 2$ peptide sequences and to $\geq 4$ spectral counts for proteins with unique peptide quantifications. Then, the $\log _{2}$ of the median of the heavy/light ratio for each protein was transformed to a z-score for asymmetrical standard deviations of the main distribution as described previously (Graumann et al., 2008). A significance value for each protein ratio was calculated from the complementary error function for the normalized distribution of the z-scores (Graumann et al., 2008), which provides an indicator of the chance that a given protein is altered in this pilot analysis. Higher chance to be altered is provided for proteins located at the end of the tails in the normalized distribution with lower significance values. Correction of significance values for multiple testing in the quantified protein data set was performed following the Benjamini and Hochberg method (Benjamini and Hochberg, 1995). A False Discovery Rate (FDR) was computed for all the significance values and FDR threshold was set to 0.01 .

Normal distribution of the variables was determined by D'Agostino \& Pearson test. Demographic and tissue-related features of the samples were compared between schizophrenia and control conditions by Fisher exact test for qualitative variables, by Student $t$-test for parametric quantitative variables, and by Mann-Whitney $U$ test for quantitative non-parametric variables. Differences of the protein levels between schizophrenia and control groups were performed by one-tailed unpaired Student's $t$-test based on the results already provided by the pilot proteomic analysis indicating the expected direction of change. Grubbs test was used to detect outliers. Spearman or Pearson correlation analyses were carried out to detect association of our molecular measures with other clinical, demographic and tissue related variables (age, postmortem delay, $\mathrm{pH}$, daily chlorpromazine equivalent dose and duration of illness). Statistical analysis was performed with GraphPad Prism version 5.00 , with significance level set to 0.05 . 
Top twenty up and down regulated proteins in the pilot proteomic analysis of the postmortem dorsolateral prefrontal cortex in schizophrenia.

\begin{tabular}{|c|c|c|c|c|c|c|c|c|}
\hline \multirow{2}{*}{$\begin{array}{l}\text { Acc. } \\
\text { number }\end{array}$} & \multirow{2}{*}{$\begin{array}{l}\text { Gene } \\
\text { symbol }\end{array}$} & \multirow[t]{2}{*}{ Protein description } & \multicolumn{2}{|c|}{$\log _{2}$ ratio $\mathrm{H} / \mathrm{L}$} & \multirow{2}{*}{$\begin{array}{l}\text { Ratio } \\
\mathrm{H} / \mathrm{L} \\
\text { Norm } \\
\text { median }\end{array}$} & \multirow[t]{2}{*}{ RBC? } & \multirow[t]{2}{*}{ Biological function } & \multirow[t]{2}{*}{ Previously reported in the dIPFC in SZ } \\
\hline & & & $\begin{array}{l}\text { Norm } \\
\text { median }\end{array}$ & SD & & & & \\
\hline Q9Y6C7 & LOH3CR2A & Loss of heterozygosity 3 chromosomal region 2 gene A protein & -5.50 & 0.29 & 0.02 & No & Unknown & \\
\hline Q6FGZ8 & TUBB & TUBB protein (fragment) $)^{\mathrm{a}}$ & -5.25 & 0.72 & 0.03 & No & Cell growth/maintenance & $\begin{array}{l}\text { V English et al. (2009), } \mathbf{\Delta} \text { Behan et al. } \\
\text { (2008) }\end{array}$ \\
\hline Q5VWI4 & NRAP & Nebulin-related anchoring protein & -4.90 & 2.18 & 0.03 & No & Cell growth/maintenance & \\
\hline XP_372916 & LOC391352 & Predicted: similar to peptidylprolyl isomerase A isoform 1 & -4.36 & 1.95 & 0.05 & No & Unknown & \\
\hline Q569K3 & LOC644936 & Actin/actin-like family protein & -3.80 & 1.31 & 0.07 & No & Cell comunication/signal transduction & \\
\hline Q5VVH4 & PHIP & Pleckstrin homology domain interacting protein & -3.74 & 1.94 & 0.07 & No & Cell comunication/signal transduction & \\
\hline P11473 & VDR & Vitamin D3 receptor & -3.54 & 1.63 & 0.09 & No & Regulation of gene expression, epigenetic & \\
\hline P22061-2 & PCMT1 & Isoform 2 of Protein-L-isoaspartate(D-aspartate) 0 -methyltransferase & -2.00 & 0.96 & 0.25 & No & Protein metabolism & $\begin{array}{l}\text { A English et al. (2009); } \\
\text { A Martins-de-Souza et al. (2009b) }\end{array}$ \\
\hline P49674 & CSNK1E & Casein kinase I isoform epsilon & -1.66 & 0.04 & 0.32 & No & Cell comunication/signal transduction & $\begin{array}{l}(\mathbf{\Delta C S N K 2 A 1 )} \text { Martins-de-Souza et al. } \\
(2009 \mathrm{~b})\end{array}$ \\
\hline P11217 & PYGM & Glycogen phosphorylase, muscle form & -1.12 & 0.31 & 0.46 & No & Metabolism/energy pathways & \\
\hline Q96DZ9-2 & CMTM5 & $\begin{array}{l}\text { Isoform } 2 \text { of CKLF-like MARVEL transmembrane domain-containing } \\
\text { protein } 5\end{array}$ & -1.07 & 0.72 & 0.48 & No & Unknown & \\
\hline P02689 & PMP2 & Myelin P2 protein & -0.96 & 0.21 & 0.51 & No & Transport & \\
\hline Q96NS9 & MAP4 & $\begin{array}{l}\text { CDNA FLJ30134 fis, clone BRACE1000187, weakly similar to } \\
\text { microtubule-associated protein } 4\end{array}$ & -0.96 & 0.56 & 0.51 & No & Cell growth/maintenance & ( $\mathbf{\Delta}$ MAP6) Martins-de-Souza et al. (2009b) \\
\hline P49753-1 & ACOT2 & Isoform 1 of acyl-coenzyme $A$ thioesterase 2 & -0.92 & 0.26 & 0.53 & No & Metabolism/energy pathways & \\
\hline Q8NF17 & IGHM & FLJ00385 protein (fragment) & -0.91 & 0.29 & 0.53 & No & Immune response & \\
\hline P12036 & NEFH & Neurofilament triplet $\mathrm{H}$ protein & -0.85 & 0.32 & 0.55 & No & Cell growth/maintenance & \\
\hline P15090 & FABP4 & Fatty acid-binding protein, adipocyte & -0.85 & 0.01 & 0.56 & No & Cell comunication/signal transduction & \\
\hline P00352 & ALDH1A1 & Retinal dehydrogenase 1 & -0.77 & 0.39 & 0.59 & Yes & $\begin{array}{l}\text { Aldehyde metabolism } \\
\text { lis }\end{array}$ & 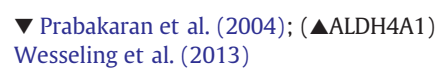 \\
\hline Q96IX5 & USMG5 & Up-regulated during skeletal muscle growth protein 5 & -0.74 & 0.11 & 0.60 & No & Unknown & \\
\hline P63000-1 & RAC1 & Isoform A of Ras-related C3 botulinum toxin substrate 1 precursor & -0.73 & 0.03 & 0.60 & No & Cell comunication/signal transduction & \\
\hline 096000 & NDUFB10 & NADH dehydrogenase [ubiquinone] 1 beta subcomplex subunit 10 & 0.68 & 0.25 & 1.61 & No & Metabolism/energy pathways & \\
\hline $\mathrm{Q} 02410$ & APBA1 & Amyloid beta A4 precursor protein-binding family A member 1 & 0.70 & 0.19 & 1.62 & No & Cell comunication/signal transduction & \\
\hline 094772 & LY6H & Lymphocyte antigen Ly-6H precursor & 0.70 & 0.00 & 1.63 & No & Immune response & \\
\hline P63027 & VAMP2 & Vesicle-associated membrane protein & 20.70 & 0.16 & 1.63 & No & Transport & \\
\hline P00403 & MT-CO2 & Cytochrome c oxidase subunit 2 & 0.71 & 0.13 & 1.64 & No & Metabolism/energy pathways & \\
\hline Q15836 & VAMP3 & Vesicle-associated membrane protein 3 & 0.73 & 0.25 & 1.66 & Yes & Transport & \\
\hline Q2TBE9 & OAT & Phospholysine phosphohistidine inorganic pyrophosphate phosphatase & 0.74 & 0.24 & 1.66 & No & Unknown & \\
\hline P55087-1 & AQP4 & Isoform 2 of aquaporin-4 & 0.75 & 0.42 & 1.68 & No & Transport & A Chan et al. (2011) \\
\hline Q9H5G0 & ISOC2 & Isochorismatase domain-containing protein 2 , mitochondrial & 0.78 & 0.36 & 1.72 & No & Metabolism/energy pathways & \\
\hline Q8NBS8 & CAMKV & $\begin{array}{l}\text { CDNA FLJ90813 fis, clone Y79AA1000967, weakly similar to } \\
\text { calcium/calmodulin-dependent protein kinase type I }\end{array}$ & 0.78 & 0.13 & 1.72 & No & Unknown & \\
\hline Q12904 & NPNT & Multisynthetase complex auxiliary component p43 & 0.79 & 0.32 & 1.73 & No & Unknown & \\
\hline P35232 & PHB & Prohibitin & 0.82 & 0.34 & 1.76 & No & Cell comunication/signal transduction & $\begin{array}{l}\text { A Behan et al. (2008); } \mathbf{\nabla} \text { Smalla et al. } \\
\text { (2008) }\end{array}$ \\
\hline Q99623 & PHB2 & Prohibitin-2 & 0.83 & 0.00 & 1.78 & No & $\begin{array}{l}\text { Regulation of nucleobase, nucleoside, nucleotide } \\
\text { and nucleic acid metabolism }\end{array}$ & $\begin{array}{l}(\mathbf{\Lambda} \text { PHB) Behan et al. (2008); ( } \mathbf{\nabla P H B}) \\
\text { Smalla et al. (2008) }\end{array}$ \\
\hline P00167-2 & CYB5A & Isoform 2 of cytochrome b5 & 0.86 & 0.16 & 1.82 & No & Metabolism/energy pathways & \\
\hline P10636-6 & MAPT & Isoform tau-D of microtubule-associated protein tau & 0.86 & 0.55 & 1.82 & No & Cell growth/maintenance & \\
\hline P62158 & CALM1 & Calmodulin & 1.13 & 0.84 & 2.20 & No & Cell comunication/signal transduction & $\boldsymbol{\nabla}$ Novikova et al. (2006) \\
\hline Q5UE58 & CLSTN1 & Calsyntenin 1 isoform 2 & 1.22 & 0.89 & 2.33 & No & Cell comunication/signal transduction & \\
\hline Q8N163-2 & KIAA1967 & Isoform 2 of protein KIAA1967 & 1.66 & 0.49 & 3.16 & No & Cell comunication/signal transduction & \\
\hline Q6ZS99 & ARMC9 & CDNA FLJ45706 fis, clone FEBRA2028457, highly similar to nucleolin & 3.08 & 1.75 & 8.43 & No & Unknown & \\
\hline Q8WZ42-2 & TTN & Isoform 2 of titin & 8.83 & 3.75 & 456.17 & No & Transport & \\
\hline
\end{tabular}

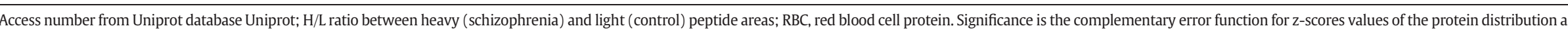
described in the methods section. Selected candidates for validation are shown in bold. Related proteins previously reported to be altered in this brain area in SZ are indicated in brackets.

a This protein comes from TUBB pseudogene which corresponds to a small fragment not the whole TUBB protein. 


\section{Results}

3.1. Proteomic analysis of postmortem DLPFC from schizophrenia patients and controls

To identify protein changes related to schizophrenia, we performed a pilot proteomic analysis in pools of DLPFC protein extracts from four male patients with schizophrenia and four control individuals matched for gender, age and postmortem delay. No differences were observed between schizophrenia and control groups for any demographic- or tissue-related variables (Table 1 ). Tryptic peptides from protein extracts were subjected to a reductive dimethylation reaction for both pools. Schizophrenia peptides were labelled heavy and control peptides were labelled light, providing a difference of 6.0377 Da for the same peptide sequence in the MS spectrum (Fig. 1). Labelled heavy and light peptides were mixed equally in a 1:1 weight proportion, separated by SCX and analyzed by LC-MS/MS (Fig. 1). We quantified 36,226 peptides corresponding to 2115 proteins with adequate quantification quality. $58 \%$ of proteins were identified with 2 or more peptides and $33 \%$ with four or more peptides (Fig. S1A). 1315 proteins were quantified with two or more unique peptide sequences and four or more spectral counts) (Supplementary Data 1 and Fig. S1B). The distribution of protein $\mathrm{H} / \mathrm{L}$ ratios shows that the majority of proteins of the DLPFC proteome were not altered in schizophrenia (Fig. S1C and S1D).

We identified 116 proteins (9\%) with a false discovery rate acceptance of $1 \%$, of which 60 were down-regulated and 56 up-regulated (Supplementary Data 2) By comparing our results with previous proteomic studies of the DLPFC, we found that $22 \%$ of the altered proteins in our list ( 26 out of 116 proteins) had been previously described for the same isoform reported here and/or a closely related protein (Behan et al., 2008; Chan et al., 2011; English et al., 2009; English et al., 2011; Johnston-Wilson et al., 2000; Martins-de-Souza et al., 2009a; Martins-de-Souza et al., 2009b; Novikova et al., 2006; Pennington et al., 2008; Prabakaran et al., 2004; Smalla et al., 2008; Wesseling et al., 2013) (Supplementary Data 2). Moreover, we restricted our candidate list to the top-20 upregulated and the top-20 downregulated proteins (Table 2). We further classified the altered proteins according to their biological function using the Human Protein Reference Database (HPRD-http://www.hprd.org) and we compared them to the nonregulated proteome. Similar biological functions were found in both data sets and no biological function was enriched (Fig. S1E). The most prevalent functions were cell communication and signaling pathways,
A

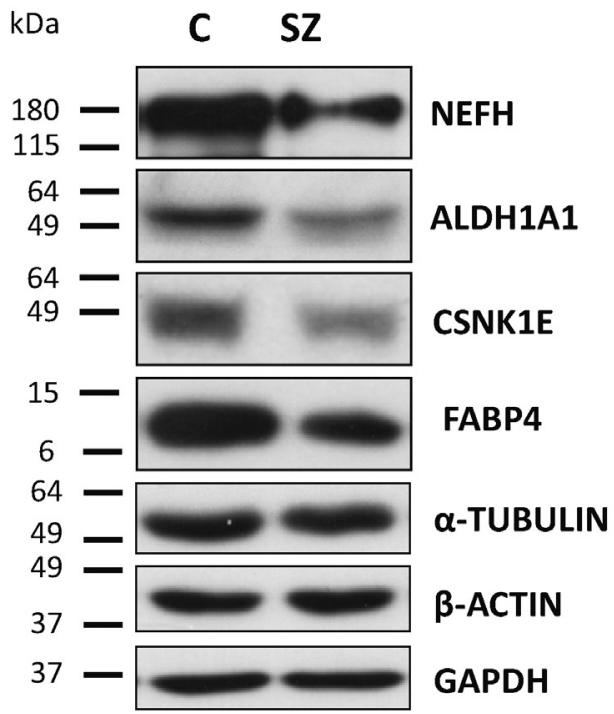

B

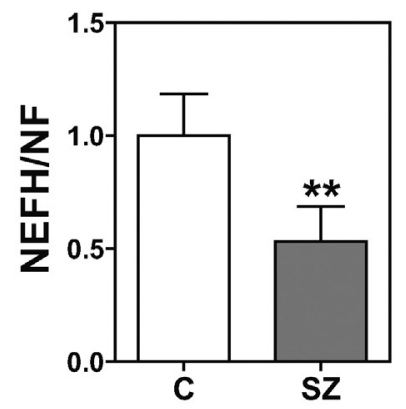

C

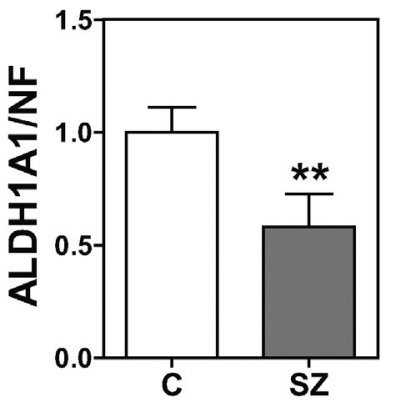

D

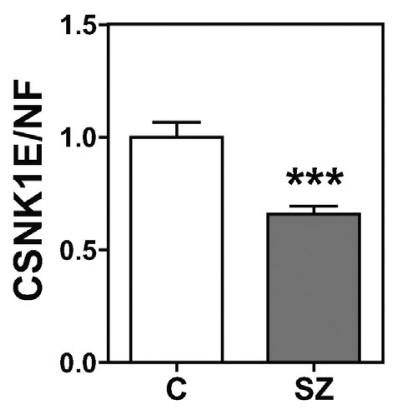

E

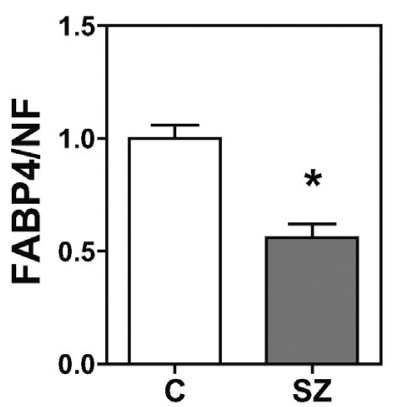

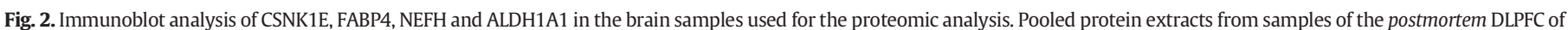

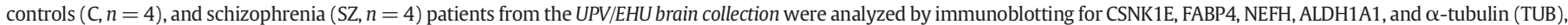

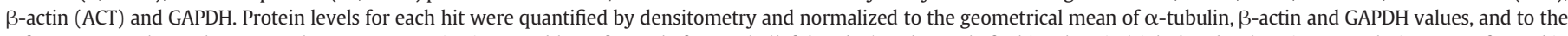

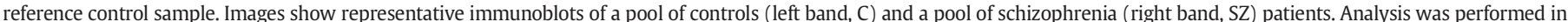

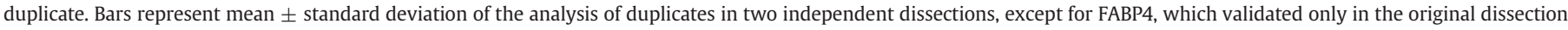

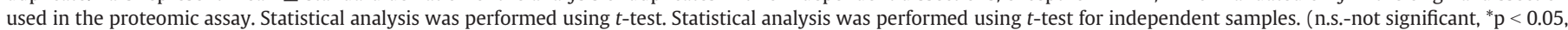
$\left.{ }^{* *} p<0.01,{ }^{* * *} p<0.001\right)$. 
metabolism and energy pathways and cell growth and maintenance (Fig. S1E).

\subsection{Validation of hit protein changes in DLPFC schizophrenia samples}

From the significantly altered and top-20 upregulated and top-20 downregulated proteins (Table 2), 4 hit candidates were selected for further validation by immunoblot due to their protein function on cell signaling, neuronal development and synapse functioning: casein kinase I isoform epsilon (CSNK1E), fatty acid-binding protein 4 (FABP4), neurofilament triplet $\mathrm{H}$ protein (NEFH), and retinal dehydrogenase 1 (ALDH1A1).

In a first phase, we analyzed the protein levels of CSNK1E, FABP4, NEFH and ALDH1A1 in pooled samples from the same cohort analyzed by proteomics. All candidates were referenced to the geometrical mean of $\alpha$-tubulin, $\beta$-actin and GAPDH levels in each pool, which showed no differences between the two pools (Fig. S2). We observed that NEFH, CSNK1E, FABP4, and ALDH1A1 protein levels were significantly decreased in schizophrenia (Fig. 2). To validate these proteins as potentially decreased proteins in DLPFC in schizophrenia, we further characterized NEFH, CSKN1E, FABP4, and ALDH1A1 protein levels by immunoblot in an independent cohort of 23 male elderly chronic

A

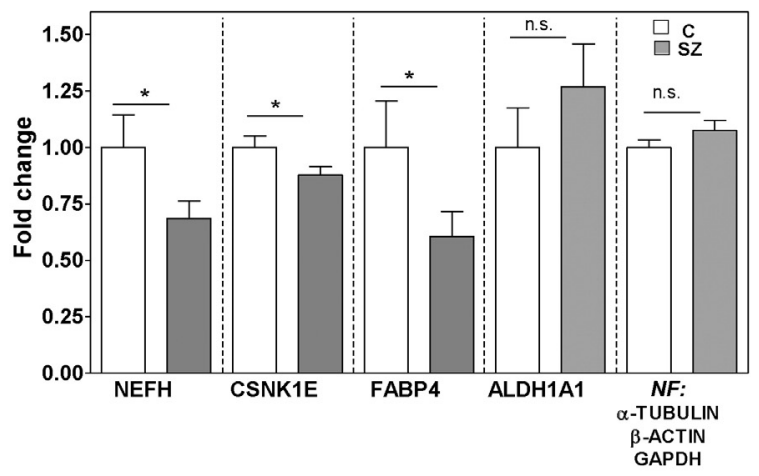

B

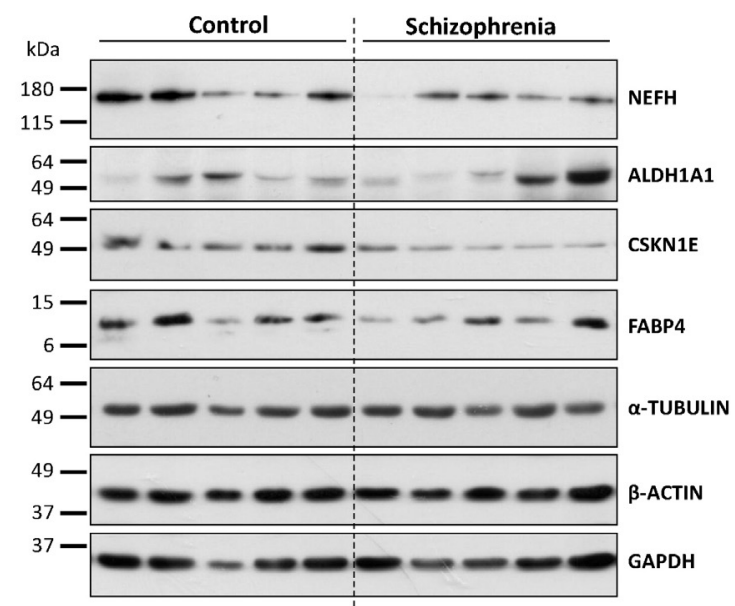

Fig. 3. CSNK1E, FABP4 and NEFH are reduced in the DLPFC of chronic schizophrenia Protein extracts from samples of the postmortem dorsolateral prefrontal cortex of control individuals ( $C, n=23$ ), and schizophrenia patients ( $S Z, n=23)$ from the collection of neurologic tissues of Parc Sanitari Sant Joan de Déu (Roca et al., 2008) and the Institute of Neuropathology Brain Bank (HUB-ICO-IDIBELL Biobank) were analyzed by immunoblot for the same proteins as in Fig. 2 and quantified by densitometry. (A) Protein levels for each protein were normalized to the geometrical mean of $\alpha$ tubulin, $\beta$-actin and GAPDH values, and to a reference healthy control sample. Bars represent mean \pm standard error of the mean for each group. Statistical analysis was performed using $t$-test for independent samples. (n.s.-not significant, ${ }^{*} p<0.05$ ). (B) Representative Western blot images for the indicated proteins in 5 control individuals and 5 patients with schizophrenia.
Table 3

Association analysis of other variables in the independent validation cohort.

\begin{tabular}{|c|c|c|c|c|}
\hline & Age & PMD & \multicolumn{2}{|r|}{$\mathrm{pH}$} \\
\hline & $r$ & $r$ & & $r$ \\
\hline \multicolumn{5}{|c|}{$\operatorname{SZ}-\mathrm{C}(n=46)$} \\
\hline CSNK1E & $-0.086^{\mathrm{a}}$ & $0.334^{\mathrm{a}^{*}}$ & & $-0.097^{\mathrm{a}}$ \\
\hline $\mathrm{FABP}^{\dagger}$ & $-0.313^{\mathrm{a}^{*}}$ & $0.010^{\mathrm{a}}$ & & $0.035^{\mathrm{a}}$ \\
\hline \multirow[t]{3}{*}{$\mathrm{NEFH}^{\dagger}$} & $0.105^{\mathrm{a}}$ & $0.030^{\mathrm{b}}$ & & $0.094^{\mathrm{b}}$ \\
\hline & \multicolumn{2}{|l|}{ Daily AP dose } & \multicolumn{2}{|c|}{ Duration of illness } \\
\hline & \multicolumn{2}{|l|}{$\mathrm{r}$} & \multicolumn{2}{|l|}{$\mathrm{r}$} \\
\hline \multicolumn{5}{|c|}{$\mathrm{SZ}(n=23)$} \\
\hline CSNK1E & $0.132^{\mathrm{b}}$ & \multicolumn{3}{|c|}{$0.015^{\mathrm{a}}$} \\
\hline FABP4 ${ }^{\dagger}$ & $0.077^{a}$ & & \multicolumn{2}{|l|}{$-0.540^{\mathrm{a}^{* *}}$} \\
\hline NEFH & $-0.418^{\mathrm{b}^{*}}$ & & \multicolumn{2}{|l|}{$-0.156^{\mathrm{a}}$} \\
\hline
\end{tabular}

PMD, postmortem delay; SZ, schizophrenia; C, control; AP, antipsychotic.

Significant associations are indicated in bold.

${ }^{a} \mathrm{r}$, Spearman's correlation for non-parametric variables.

b r', Pearson's $r$ for parametric variables.

$\uparrow$ An outlier was detected for NEFH, and two outliers for FABP4 and therefore excluded from the analysis (NEFH: C, $n=22, \mathrm{SZ}, n=23$; FABP4: C, $n=22$, SZ group, $n=22$ ).

$*$ Last chlorpromazine equivalent dose was calculated based on the electronic records of drug prescriptions of the patients.

$* p<0.05$.

** $p<0.01$.

schizophrenia patients and 23 matched controls (Table 1). We found that the following protein levels were significantly reduced in the schizophrenia group: NEFH $[t=1.917, \mathrm{df}=44 ; p=0.0308$; fold change (FC) \pm SEM: control $(C)=1.000 \pm 0.1449, \mathrm{SZ}=0.6856 \pm$ $0.0768]$, CSNK1E $[t=1.942, \mathrm{df}=44 ; p=0.0293$; FC \pm SEM: $\mathrm{C}=$ $1.000 \pm 0.0511, \mathrm{SZ}=0.8773 \pm 0.0372]$ and FABP4 $[t=1.693, \mathrm{df}=$ $42 ; p=0.0489 ; \mathrm{FC} \pm \mathrm{SEM}: \mathrm{C}=1.000 \pm 0.2052, \mathrm{SZ}=0.6050 \pm$ 0.1110] (Fig. 3). However, ALDH1A1 was not significantly altered in this cohort $(t=1.036, \mathrm{df}=43 ; p=0.1530 ; \mathrm{FC} \pm \mathrm{SEM}: \mathrm{C}=1.000 \pm$ $0.1752, \mathrm{SZ}=1.268 \pm 0.1898$ ) (Fig. 3 ). This protein is the only candidate that was previously reported to be expressed in the red cell blood proteome (Pasini et al., 2006) (Supplementary Data 2), which could be a confounding factor for ALDH1A1, but not for the other candidates not expressed in red blood cells. Further, we have analyzed the influence of other demographic, clinical and tissue-related variables (Table 3). FABP4 and CSNK1E showed significant correlations with age (Spearman's $r=-0.313, p=0.039$ ) and PMD (Spearman's $r=$ $0.334, p=0.023$ ), respectively. However, there are no significant differences in age and PMD between groups (Table 1). NEFH protein levels inversely correlated with the chlorpromazine equivalent dose (Pearson's $r=-0.418, p=0.047 n=23$ ), indicating that NEFH may be influenced by antipsychotic treatments. FABP4 protein levels negatively correlated with the duration of the illness (FABP4: Spearman's $\mathrm{r}=-0.540, p=0.009, n=22$ ), suggesting that this protein may be changing with the progression of the disease.

\section{Discussion}

This study reveals novel altered proteins in the DLPFC in schizophrenia including NEFH, CSNK1E, and FABP4. A decrease in the abundance of these proteins may be associated with cognitive and/or negative symptoms of schizophrenia.

\subsection{Neurofilament triplet $H$ protein}

$\mathrm{NEFH}$ is a component of the neurofilament intermediate proteins found in the cytoskeleton of mature neurons that regulates axon caliber (Lee and Cleveland, 1996). There are previous reports of altered protein levels of NEFH, neurofilament triplet light protein (NEFL) and neurofilament triplet medium protein (NEFM) in schizophrenia (English et al., 2009; English et al., 2011; Focking et al., 2011; Martins-de-Souza et al., 
2010a; Martins-de-Souza et al., 2010b; Martins-de-Souza et al., 2010c). In addition, a role for NEFM and NEFL in connectivity functions in schizophrenia has also been suggested (English et al., 2011), with an impact on synapses and plasticity, core features of the disorder (Friston, 1999; Harrison and Weinberger, 2005). Here we describe for the first time a reduction in NEFH protein levels in grey matter in schizophrenia patients. Therefore, a dysregulation of NEFH protein levels together with the other neurofilament proteins is likely to have a role in the connectivity deficits present in this disorder, participating in the neuropathology of schizophrenia.

\subsection{Casein kinase I isoform epsilon}

We describe a reduction in CSNK1E protein levels in the postmortem DLPFC in schizophrenia. CSNK1E is a member of the clock gene family that regulates signal transduction pathways related to the circadian molecular clock (Ko and Takahashi, 2006). Sleep and circadian rhythms abnormalities are often a co-morbidity in schizophrenia, suggesting common brain mechanisms (Klingaman et al., 2015; Pritchett et al., 2012). Cognitive impairments occur in sleep and circadian rhythm disruption as well as in schizophrenia (Pritchett et al., 2012). This together with our finding that CSNK1E expression is reduced in schizophrenia suggests that the molecular clock pathway in the prefrontal cortex may have a role in cognitive deficits in both disorders. More work is needed to investigate this possibility.

\subsection{Fatty acid-binding protein 4}

FABP4 is a member of the FABP family of proteins whose primary role is facilitating the uptake and intracellular transport of hydrophobic fatty acids and so participating in energy metabolism, signaling pathways and regulation of transcription (Chmurzynska, 2006). Although FABP4 is typically expressed in adipocytes and macrophages, we have detected it in human postmortem brain by mass spectrometry and an isoform-specific antibody, in line with previous reports (Anderson et al., 2011; Chaerkady et al., 2011). We found that FABP4 protein levels are decreased in schizophrenia patients. Notably, a recent study reported a reduction in FABP4 expression in the scalp hair follicle in patients with schizophrenia in an attempt to provide more accessible biomarkers for this disorder (Maekawa et al., 2015). This report also analyzed FABP4 gene expression in the brains but found no changes in Brodmann area 46. Interestingly, here we have found that FABP4 protein levels are reduced in Brodmann area 9, further suggesting a role for FABP4 in the pathology of schizophrenia. Despite the role of FABP4 in brain function is unknown, it has been reported that other FABP proteins such as FABP3, FABP5 and FABP7 play important roles in brain development (Liu et al., 2010). These additional FABP proteins facilitate the cellular functions of long chain polyunsaturated fatty acids (PUFAs), which have also been linked to schizophrenia (Freeman, 2000; Maekawa et al., 2011). PUFAs are essential for the normal development of the brain (Basak et al., 2013; Neuringer et al., 1988; Wainwright, 2002), participate in synaptic vesicle trafficking (Ben Gedalya et al., 2009), and have been related to altered dopamine vesicle density in rat frontal cortex (Zimmer et al., 2000) and behavioral disturbances (Bourre et al., 1989; Yoshida et al., 1997). Therefore, we suggest that a decrease in FABP4 in schizophrenia could be limiting vesicle formation in the presynaptic terminal. However, further studies will be needed to confirm this mechanism.

\subsection{Retinal dehydrogenase 1}

ALDH1A1 appeared to be altered in the pool of the smaller cohort but this was not replicated in the larger cohort used in this study, comprising tissue from older individuals. This could be a consequence of ALDH1A1 being part of the red blood cell proteome (Pasini et al., 2006) and therefore a false positive or may be the result of an alteration present in only one patient. However, this protein has been previously described as being reduced in white matter in the DLPFC in schizophrenia (Prabakaran et al., 2004) and regulated by psychotropic drugs in the context of Parkinson Disease (Lauterbach, 2012). The closely related protein ALDH1A2 has also been associated with schizophrenia previously (Wan et al., 2009). Therefore, further studies should be conducted to determine whether this factor is associated with the pathophysiology of schizophrenia.

\subsection{Limitations}

The use of human postmortem brain constitutes a useful tool to dissect the molecular mechanisms disrupted in psychiatric disorders, but has limitations. Therefore, although potentially interesting, the molecular findings of this study should be further interrogated for functional validity using orthogonal techniques. First, our pilot proteomic analysis used pooled samples. This type of design is a useful approach for rapidly detecting common altered pathways (Behan et al., 2008; Martins-de-Souza et al., 2009a; Martins-de-Souza et al., 2009b); however, it does not allow for the control of inter-individual variations, which, as noted for ALDH1A1, could account for modifications in the results. A cautious interpretation of this panel of altered protein should be considered. Further validation in individual samples will be needed for this list of possible altered candidates. Second, the possible effect of laterality in our sample cannot be ruled out, since only contralateral prefrontal cortex was available for the nonpsychiatric control group. Left schizophrenia prefrontal cortex was compared to right control prefrontal cortex. Further analyses should be performed to explore the laterality effects on the abundance of these proteins in the prefrontal cortex and their potential as biomarkers. To investigative their possible role as biomarkers it would be of great interest to extend the study of these candidates to tissues that can be studied with less invasive approaches such as cerebrospinal fluid (CSF) and peripheral blood cells. Third, the patients in our second validation cohort had long-lasting and heterogeneous antipsychotic medications. To control for this variable, we have used the last daily chlorpromazine equivalent dose in a bivariate analysis. We found that NEFH significantly correlated with the antipsychotic dose suggesting that the reduction of NEFH observed in this study could be the result of the antipsychotic treatments. Further pharmacological studies in cellular and animal models, as well as in drug naive patients, will help to clarify the possible influence of antipsychotic treatments in these candidate proteins. Fourth, we had elderly patients and matched controls in this study. Fifth, the study only included men. Further studies in a younger cohort with equal representation of both genders and if possible drug naive patients would be of interest. Finally, we were not able to validate the findings for ALDH1A1 in the larger cohort. This protein has also been described in the red cell proteome (Pasini et al., 2006). This raised the question whether some changes may be related to the presence of blood in the samples. A careful post-hoc analysis of candidates expressed in red blood cells should be taken in postmortem tissue analysis to address this potential confound. Despite these limitations, findings from this study may contribute towards a better understanding of the molecular mechanisms that underlie schizophrenia.

\subsection{Conclusions}

Our findings in the DLPFC in schizophrenia provide evidence of altered proteins involved in synaptic function (FABP4), cytoarchitecture organization (NEFH), and circadian molecular clock signaling (CSNK1E), which may be contributing to the cognitive and/or negative symptoms in this disorder. Moreover, FABP4, CSNK1E and NEFH could become potentially useful biomarkers for schizophrenia in the future.

Supplementary data to this article can be found online at http://dx. doi.org/10.1016/j.schres.2016.04.050. 


\section{Role of funding source}

The funding bodies had no role in study design, in collection, analyses and interpretation of the data, in the writing of the article, or in the decision to submit the paper for publication.

\section{Contributors}

Author RP performed human postmortem tissue dissection and validation expression measurements, analyzed validation results, performed the statistical analysis, and cowrote the first draft of the manuscript. Author NV carried out the postmortem tissue processing and did expression measurements. Author JJM contributed to the discussion of the results. IF carried out the histological analysis and contributed to the discussion of the results. $\mathrm{AB}$ contributed to the samples clinical database. Author JMH designed and implemented the clinical protocol and contributed to the discussion of the results. Author JV co-designed and implemented the proteomic analysis, discussed results and contributed to manuscript writing. Author BR designed the study, performed the processing of human postmortem tissue samples in the proteomic analysis, analyzed the proteomic results, supervised the protein expression analysis, and co-wrote the first draft of the manuscript. All authors contributed to and approved the final manuscript.

\section{Conflict of interest}

All authors declare that they have no conflicts of interest.

\section{Acknowledgements}

These studies were supported by Predoctoral Fellowship Program from ISCIII (PFIS) FI10/00177 to R.P. and the Centro de Investigación Biomédica en Red de Salud Mental (CIBERSAM) (CB/07/09/0028) to B.R. and J.M.H. Financial support of this work comes from Marie Curie Program IRG RTD REG/T.2 (2007)D/530573 to B.R., Plan Nacional de Investigación BFU2008-01103 (MCINN) to B.R. and SAF2009-08460 to J.J.M. The authors thank the donors and their families for the donation of their brains; the collaboration of the staff members of the Basque Institute of Legal Medicine for their help.

\section{References}

Anderson, G.D., Farin, F.M., Bammler, T.K., Beyer, R.P., Swan, A.A., Wilkerson, H.W., Kantor, E.D., Hoane, M.R., 2011. The effect of progesterone dose on gene expression after traumatic brain injury. J. Neurotrauma 28 (9), 1827-1843.

Baek, D., Villen, J., Shin, C., Camargo, F.D., Gygi, S.P., Bartel, D.P., 2008. The impact of microRNAs on protein output. Nature 455 (7209), 64-71.

Basak, S., Das, M.K., Duttaroy, A.K., 2013. Fatty acid-induced angiogenesis in first trimester placental trophoblast cells: possible roles of cellular fatty acid-binding proteins. Life Sci. 93 (21), 755-762.

Behan, A.T., Byrne, C., Dunn, M.J., Cagney, G., Cotter, D.R., 2008. Proteomic analysis of membrane microdomain-associated proteins in the dorsolateral prefrontal cortex in schizophrenia and bipolar disorder reveals alterations in LAMP, STXBP1 and BASP1 protein expression. Mol. Psychiatry 14 (6), 601-613.

Ben Gedalya, T., Loeb, V., Israeli, E., Altschuler, Y., Selkoe, D.J., Sharon, R., 2009. Alphasynuclein and polyunsaturated fatty acids promote clathrin-mediated endocytosis and synaptic vesicle recycling. Traffic 10 (2), 218-234.

Benjamini, Y., Hochberg, Y., 1995. Controlling the false discovery rate: a practical and powerful approach to multiple testing. J. R. Stat. Soc. Ser. B 57, 289-300.

Bourre, J.M., Francois, M., Youyou, A., Dumont, O., Piciotti, M., Pascal, G., Durand, G., 1989. The effects of dietary alpha-linolenic acid on the composition of nerve membranes, enzymatic activity, amplitude of electrophysiological parameters, resistance to poisons and performance of learning tasks in rats. J. Nutr. 119 (12), 1880-1892.

Braak, H., Braak, E., 1991. Neuropathological stageing of Alzheimer-related changes. Acta Neuropathol. 82 (4), 239-259.

Braak, H., Alafuzoff, I., Arzberger, T., Kretzschmar, H., Del Tredici, K., 2006. Staging of Alzheimer disease-associated neurofibrillary pathology using paraffin sections and immunocytochemistry. Acta Neuropathol. 112 (4), 389-404.

Chaerkady, R., Letzen, B., Renuse, S., Sahasrabuddhe, N.A., Kumar, P., All, A.H., Thakor, N.V., Delanghe, B., Gearhart, J.D., Pandey, A., Kerr, C.L., 2011. Quantitative temporal proteomic analysis of human embryonic stem cell differentiation into oligodendrocyte progenitor cells. Proteomics 11 (20), 4007-4020.

Chan, M.K., Tsang, T.M., Harris, L.W., Guest, P.C., Holmes, E., Bahn, S., 2011. Evidence for disease and antipsychotic medication effects in post-mortem brain from schizophrenia patients. Mol. Psychiatry 16 (12), 1189-1202.

Chmurzynska, A., 2006. The multigene family of fatty acid-binding proteins (FABPs): function, structure and polymorphism. J. Appl. Genet. 47 (1), 39-48.

English, J.A., Dicker, P., Focking, M., Dunn, M.J., Cotter, D.R., 2009. 2-D DIGE analysis implicates cytoskeletal abnormalities in psychiatric disease. Proteomics 9 (12), 3368-3382.

English, J.A., Pennington, K., Dunn, M.J., Cotter, D.R., 2011. The Neuroproteomics of Schizophrenia. Biol. Psychiatry 69 (2), 163-172.

Focking, M., Dicker, P., English, J.A., Schubert, K.O., Dunn, M.J., Cotter, D.R., 2011. Common proteomic changes in the hippocampus in schizophrenia and bipolar disorder and particular evidence for involvement of cornu ammonis regions 2 and 3. Arch. Gen. Psychiatry 68 (5), 477-488.

Freeman, M.P., 2000. Omega-3 fatty acids in psychiatry: a review. Ann. Clin. Psychiatry 12 (3), 159-165.

Friston, K.J., 1999. Schizophrenia and the disconnection hypothesis. Acta Psychiatr. Scand. Suppl. 395, 68-79.
Frith, C., Dolan, R., 1996. The role of the prefrontal cortex in higher cognitive functions. Brain Res. Cogn. Brain Res. 5 (1-2), 175-181.

Gardner, D.M., Murphy, A.L., O'Donnell, H., Centorrino, F., Baldessarini, R.J., 2010. International consensus study of antipsychotic dosing. Am. J. Psychiatry 167 (6), 686-693.

Gold, J.M., 2004. Cognitive deficits as treatment targets in schizophrenia. Schizophr. Res. $72(1), 21-28$.

Goldstein, J.M., Goodman, J.M., Seidman, L.J., Kennedy, D.N., Makris, N., Lee, H., Tourville, J., Caviness Jr., V.S., Faraone, S.V., Tsuang, M.T., 1999. Cortical abnormalities in schizophrenia identified by structural magnetic resonance imaging. Arch. Gen. Psychiatry 56 (6), 537-547.

Graumann, J., Hubner, N.C., Kim, J.B., Ko, K., Moser, M., Kumar, C., Cox, J., Scholer, H., Mann, M., 2008. Stable isotope labeling by amino acids in cell culture (SILAC) and proteome quantitation of mouse embryonic stem cells to a depth of 5,111 proteins. Mol. Cell. Proteomics 7 (4), 672-683.

Harrison, P.J. Weinberger, D.R., 2005. Schizophrenia genes, gene expression, and neuropathology: on the matter of their convergence. Mol. Psychiatry 10 (1), 40-68.

Johnston-Wilson, N.L., Sims, C.D., Hofmann, J.P., Anderson, L., Shore, A.D., Torrey, E.F., Yolken, R.H., 2000. Disease-specific alterations in frontal cortex brain proteins in schizophrenia, bipolar disorder, and major depressive disorder. The Stanley Neuropathology Consortium. Mol. Psychiatry 5 (2), 142-149.

Khidekel, N., Ficarro, S.B., Clark, P.M., Bryan, M.C., Swaney, D.L., Rexach, J.E., Sun, Y.E., Coon, J.J., Peters, E.C., Hsieh-Wilson, L.C., 2007. Probing the dynamics of O-GlcNAc glycosylation in the brain using quantitative proteomics. Nat. Chem. Biol. 3 (6), 339-348.

Kienast, T., Heinz, A., 2006. Dopamine and the diseased brain. CNS Neurol. Disord. Drug Targets 5 (1), 109-131.

Klingaman, E.A., Palmer-Bacon, J., Bennett, M.E., Rowland, L.M., 2015. Sleep disorders among people with schizophrenia: emerging research. Curr. Psychiatry Rep. 17 (10), 616.

Ko, C.H., Takahashi, J.S., 2006. Molecular components of the mammalian circadian clock. Hum. Mol. Genet. 15 (2), R271-R277.

Konradi, C., 2005. Gene expression microarray studies in polygenic psychiatric disorders: applications and data analysis. Brain Res. Brain Res. Rev. 50 (1), 142-155.

Krystal, J.H., Karper, L.P., Seibyl, J.P., Freeman, G.K., Delaney, R., Bremner, J.D., Heninger, G.R., Bowers Jr., M.B., Charney, D.S., 1994. Subanesthetic effects of the noncompetitive NMDA antagonist, ketamine, in humans. Psychotomimetic, perceptual, cognitive, and neuroendocrine responses. Arch. Gen. Psychiatry 51 (3), 199-214.

Lauterbach, E.C., 2012. Psychotropics regulate Skp1a, Aldh1a1, and Hspa8 transcription-potential to delay Parkinson's disease. Prog. Neuro-Psychopharmacol. Biol. Psychiatry 40, 236-239.

Lee, M.K., Cleveland, D.W., 1996. Neuronal intermediate filaments. Annu. Rev. Neurosci. 19, 187-217.

Lewis, D.A., Moghaddam, B., 2006. Cognitive dysfunction in schizophrenia: convergence of gamma-aminobutyric acid and glutamate alterations. Arch. Neurol. 63 (10), 1372-1376.

Liu, R.Z., Mita, R., Beaulieu, M., Gao, Z., Godbout, R., 2010. Fatty acid binding proteins in brain development and disease. Int. J. Dev. Biol. 54 (8-9), 1229-1239.

Maekawa, M., Owada, Y., Yoshikawa, T., 2011. Role of polyunsaturated fatty acids and fatty acid binding protein in the pathogenesis of schizophrenia. Curr. Pharm. Des. 17 (2), 168-175.

Maekawa, M., Yamada, K., Toyoshima, M., Ohnishi, T., Iwayama, Y., Shimamoto, C., Toyota, T., Nozaki, Y., Balan, S., Matsuzaki, H., Iwata, Y., Suzuki, K., Miyashita, M., Kikuchi, M., Kato, M., Okada, Y., Akamatsu, W., Mori, N., Owada, Y., Itokawa, M., Okano, H., Yoshikawa, T., 2015. Utility of scalp hair follicles as a novel source of biomarker genes for psychiatric illnesses. Biol. Psychiatry 78 (2), 116-125.

Mai, J.K., Assheuer, J., Paxinos, G., 1997. Atlas of the Human Brain. Academic Press, San Diego.

Martins-de-Souza, D., Gattaz, W.F., Schmitt, A., Maccarrone, G., Hunyadi-Gulyas, E., Eberlin, M.N., Souza, G.H., Marangoni, S., Novello, J.C., Turck, C.W., Dias-Neto, E., 2009a. Proteomic analysis of dorsolateral prefrontal cortex indicates the involvement of cytoskeleton, oligodendrocyte, energy metabolism and new potential markers in schizophrenia. J. Psychiatr. Res. 43 (11), 978-986.

Martins-de-Souza, D., Gattaz, W.F., Schmitt, A., Rewerts, C., Maccarrone, G., Dias-Neto, E., Turck, C.W., 2009b. Prefrontal cortex shotgun proteome analysis reveals altered calcium homeostasis and immune system imbalance in schizophrenia. Eur. Arch. Psychiatry Clin. Neurosci. 259 (3), 151-163.

Martins-de-Souza, D., Dias-Neto, E., Schmitt, A., Falkai, P., Gormanns, P., Maccarrone, G., Turck, C.W., Gattaz, W.F., 2010a. Proteome analysis of schizophrenia brain tissue. World J. Biol. Psychiatry 11 (2), 110-120.

Martins-de-Souza, D., Maccarrone, G., Wobrock, T., Zerr, I., Gormanns, P., Reckow, S., Falkai, P., Schmitt, A., Turck, C.W., 2010b. Proteome analysis of the thalamus and cerebrospinal fluid reveals glycolysis dysfunction and potential biomarkers candidates for schizophrenia. J. Psychiatr. Res. 44 (16), 1176-1189.

Martins-de-Souza, D., Schmitt, A., Roder, R., Lebar, M., Schneider-Axmann, T., Falkai, P., Turck, C.W., 2010c. Sex-specific proteome differences in the anterior cingulate cortex of schizophrenia. J. Psychiatr. Res. 44 (14), 989-991.

Millan, M.J., Fone, K., Steckler, T., Horan, W.P., 2014. Negative symptoms of schizophrenia: clinical characteristics, pathophysiological substrates, experimental models and prospects for improved treatment. Eur. Neuropsychopharmacol. 24 (5), 645-692.

Moghaddam, B., Javitt, D., 2012. From revolution to evolution: the glutamate hypothesis of schizophrenia and its implication for treatment. Neuropsychopharmacology 37 (1), 4-15.

Neuringer, M., Anderson, G.J., Connor, W.E., 1988. The essentiality of n-3 fatty acids for the development and function of the retina and brain. Annu. Rev. Nutr. 8, 517-541.

Novikova, S.I., He, F., Cutrufello, N.J., Lidow, M.S., 2006. Identification of protein biomarkers for schizophrenia and bipolar disorder in the postmortem prefrontal 
cortex using SELDI-TOF-MS ProteinChip profiling combined with MALDI-TOF-PSDMS analysis. Neurobiol. Dis. 23 (1), 61-76.

Pasini, E.M., Kirkegaard, M., Mortensen, P., Lutz, H.U., Thomas, A.W., Mann, M., 2006. Indepth analysis of the membrane and cytosolic proteome of red blood cells. Blood 108 (3), 791-801.

Pennington, K., Beasley, C.L., Dicker, P., Fagan, A., English, J., Pariante, C.M., Wait, R., Dunn, M.J., Cotter, D.R., 2008. Prominent synaptic and metabolic abnormalities revealed by proteomic analysis of the dorsolateral prefrontal cortex in schizophrenia and bipolar disorder. Mol. Psychiatry 13 (12), 1102-1117.

Pinacho, R., Villalmanzo, N., Lalonde, J., Haro, J.M., Meana, J.J., Gill, G., Ramos, B., 2011. The transcription factor SP4 is reduced in postmortem cerebellum of bipolar disorder subjects: control by depolarization and lithium. Bipolar Disord. 13 (5-6), 474-485.

Prabakaran, S., Swatton, J.E., Ryan, M.M., Huffaker, S.J., Huang, J.T., Griffin, J.L., Wayland, M., Freeman, T., Dudbridge, F., Lilley, K.S., Karp, N.A., Hester, S., Tkachev, D., Mimmack, M.L., Yolken, R.H., Webster, M.J., Torrey, E.F., Bahn, S., 2004. Mitochondrial dysfunction in schizophrenia: evidence for compromised brain metabolism and oxidative stress. Mol. Psychiatry 9 (7), 684-697 (643).

Pritchett, D., Wulff, K., Oliver, P.L., Bannerman, D.M., Davies, K.E., Harrison, P.J., Peirson, S.N., Foster, R.G., 2012. Evaluating the links between schizophrenia and sleep and circadian rhythm disruption. J. Neural Transm. 119 (10), 1061-1075.

Roca, M., Escanilla, A., Monje, A., Baño, V., Planchat, L., Costa, J., Haro, J., 2008. Banco de tejidos neurológicos de Sant Joan de Déu-Serveis de Salut Mental para la investigación de las enfermedades mentales. La importancia de un programa de donación en vida. Psiquiatría Biológica 15 (3), 73-79.

Semkovska, M., Bedard, M.A., Stip, E., 2001. Hypofrontality and negative symptoms in schizophrenia: synthesis of anatomic and neuropsychological knowledge and ecological perspectives. L'Encéphale 27 (5), 405-415.

Smalla, K.H., Mikhaylova, M., Sahin, J., Bernstein, H.G., Bogerts, B., Schmitt, A., van der Schors, R., Smit, A.B., Li, K.W., Gundelfinger, E.D., Kreutz, M.R., 2008. A comparison of the synaptic proteome in human chronic schizophrenia and rat ketamine psychosis suggest that prohibitin is involved in the synaptic pathology of schizophrenia. Mol. Psychiatry 13 (9), 878-896.

Stahl, S.M., Buckley, P.F., 2007. Negative symptoms of schizophrenia: a problem that wil not go away. Acta Psychiatr. Scand. 115 (1), 4-11.

Sullivan, P.F., 2012. Puzzling over schizophrenia: schizophrenia as a pathway disease. Nat Med. 18 (2), 210-211.

Teffer, K., Semendeferi, K., 2012. Human prefrontal cortex: evolution, development, and pathology. Prog. Brain Res. 195, 191-218.

Toda, M., Abi-Dargham, A., 2007. Dopamine hypothesis of schizophrenia: making sense of it all. Curr. Psychiatry Rep. 9 (4), 329-336.

Wainwright, P.E., 2002. Dietary essential fatty acids and brain function: a developmental perspective on mechanisms. Proc. Nutr. Soc. 61 (1), 61-69.

Wan, C., Shi, Y., Zhao, X., Tang, W., Zhang, M., Ji, B., Zhu, H., Xu, Y., Li, H., Feng, G., He, L. 2009. Positive association between ALDH1A2 and schizophrenia in the Chinese population. Prog. Neuro-Psychopharmacol. Biol. Psychiatry 33 (8), 1491-1495.

Wesseling, H., Chan, M.K., Tsang, T.M., Ernst, A., Peters, F., Guest, P.C., Holmes, E., Bahn, S. 2013. A combined metabonomic and proteomic approach identifies frontal cortex changes in a chronic phencyclidine rat model in relation to human schizophrenia brain pathology. Neuropsychopharmacology 38 (12), 2532-2544.

Wong, A.H., Van Tol, H.H., 2003. Schizophrenia: from phenomenology to neurobiology. Neurosci. Biobehav. Rev. 27 (3), 269-306.

Yoshida, S., Yasuda, A., Kawazato, H., Sakai, K., Shimada, T., Takeshita, M., Yuasa, S. Kobayashi, T., Watanabe, S., Okuyama, H., 1997. Synaptic vesicle ultrastructural changes in the rat hippocampus induced by a combination of alpha-linolenate deficiency and a learning task. J. Neurochem. 68 (3), 1261-1268.

Zimmer, L., Delpal, S., Guilloteau, D., Aioun, J., Durand, G., Chalon, S., 2000. Chronic n-3 polyunsaturated fatty acid deficiency alters dopamine vesicle density in the rat frontal cortex. Neurosci. Lett. 284 (1-2), 25-28. 